\title{
Blood Pressure Profiles And Determinants Of Hypertension Among Public Secondary School Students In Nnewi, Southeast Nigeria
}

\author{
E.F. Ugochukwu, C.U. Onubogu, V.C. Ofora, K.N. Okeke and C.M. Uju
}

\begin{abstract}
Background: Hypertension and associated factors among adolescents have not been given the deserved attention in health care, more so as hypertensive children end up as hypertensive adults with serious co-morbidities. This is even more expedient among public school students, who in our environment are generally of lower socioeconomic status than those in private schools.
\end{abstract}

Objective: To determine the BP profiles and association of obesity indicators, socioeconomic level and physical activity with hypertension among public secondary school students.

Methodology: A cross-sectional school-based assessment of blood pressure (BP), body mass index (BMI), weight to height ratio (WHR), waist circumference (WC), physical activity and socioeconomic level among 593 students aged 10 - 17 years in public schools in Nnewi, Southeast Nigeria was carried out.

Results: The mean systolic BP increased with age and was higher for girls than for boys. The prevalence of systolic hypertension and prehypertension were $8.4 \%$ and $6.6 \%$ respectively, while that of diastolic hypertension and prehypertension were $5.7 \%$ and $11.8 \%$ respectively. Both systolic and diastolic hypertension occurred in $2.4 \%$ of students. Girls had a higher prevalence of hypertension - both systolic and diastolic. There was no significant gender difference in the prevalence of systolic hypertension and prehypertension between early and late adolescents. Early adolescent males were more likely to have diastolic hypertension and prehypertension compared to late adolescent males, while no difference in prevalence was noted among the females. Systolic hypertension was more evident in the lower socioeconomic level, those with minimal physical activity, and those in the obese/overweight categories of BMI, WC, and WHR.

Conclusion: There is a noteworthy prevalence of hypertension among adolescent public secondary school students in Nnewi. This was significantly higher among the female gender, lower socioeconomic level and students with minimal physical activity. Waist circumference in the obese/overweight category very likely predicts hypertension.

Index Terms - adolescent; blood pressure; hypertension; public school student.

Published on June 11, 2020

Ebelechuku F. Ugochukwu, Nnamdi Azikiwe University, Nigeria.

(corresponding e-mail: ef.ugochukwu@ unizik.edu.ng).

Chinyere U. Onubogu, Nnamdi Azikiwe University, Nigeria

(e-mail: cu.onubogu@ ${ }^{\text {unizik.edu.ng). }}$

Victoria C. Ofora, Nnamdi Azikiwe University Teaching Hospital, Nigeria.

(e-mail: victoriaofora1@ gmail.com).

Kenneth N. Okeke, Nnamdi Azikiwe University, Nigeria.

(e-mail: kn.okeke ${ }^{@}$ unizik.edu.ng).

Chinenye M. Uju, Nnamdi Azikiwe University Teaching Hospital, Nigeria.

(e-mail: ujuisidore@yahoo.co.uk).

\section{INTRODUCTION}

Hitherto high BP in children had been thought to result solely from secondary causes such as renal parenchymal or renovascular disease, but recently elevated levels of BP in some adolescents have been found to represent early onset of essential hypertension [1]. There is evidence that adult systemic arterial hypertension has its onset in childhood, but the diagnosis in children is often missed due to its nonspecific manifestations [2]. Various studies have given a prevalence of adolescent hypertension as ranging from $3.4 \%$ to $21.4 \%$ [3]-[9]. This in essence makes BP evaluation in adolescents, a necessary aspect of routine physical examination, to detect BP values in the elevated and normal high ranges in this age bracket, in order to institute early treatment, thereby averting long term complications of the disease.

A child or adolescent is considered hypertensive when systolic blood pressure (SBP) and/or diastolic blood pressure (DBP) is repeatedly measured at values at or above the 95th percentile for gender, age and height. SBP and DBP less than the 90th percentile are considered normal. Highnormal BP, otherwise known as prehypertension occurs when SBP and DBP are greater than or equal to the 90th but less than the 95 th percentile.

Overweight and obesity have been found to have a strong correlation with primary hypertension in children [10]-[12]. Sedentary living with limited physical activity, in these days of prolonged screen time and lack of sporting activities, fuel an increase in obesity and overweight. In the developed world lower socioeconomic status has been reported to favor higher BP during childhood and adulthood [13], [14], as this group of persons tend to be more obese and have more behavioral risk factors.

Children do not commonly have their BP measured as frequently as adults do in clinical settings. Most times secondary school students only get examined at school entry to enable entry point issuance of medical certificates as required. Even then, the BP may not still be measured, or not properly interpreted where measured. This study therefore, set out to determine the $\mathrm{BP}$ profiles and association of obesity indicators, such as BMI, WHR, WC, as well as socioeconomic level (according to a modification of Oyedeji's classification [15] and physical activity with hypertension among public secondary school students in Nnewi metropolis, in southeast Nigeria. 


\section{SubJECTS AND Methods}

\section{A. Study Area and Population}

The study was conducted from September to December 2014 in Nnewi North Local Government Area (LGA) of Anambra State, South-East Nigeria. Nnewi North is a one town LGA. Most of the inhabitants are traders, civil servants or subsistence farmers, and the predominant religion is Christianity.

The study population was apparently healthy adolescent students of public secondary schools in Nnewi, aged 10 to 17 years. There were eight public secondary schools in Nnewi consisting of three all-girls' schools, two all-boys' schools and three coeducational schools with a total population of 8495 students. This population comprised of 5329 juniors and 3166 senior secondary students. The male to female ratio was 0.9: 1 which was distributed as 2500 boys and 2829 girls in the junior classes; while 1441 boys and 1725 girls were in the senior classes.

\section{B. Study Design and Subject Selection}

This was a cross-sectional descriptive study of 593 adolescent public secondary school students in Nnewi. The study participants were recruited using multi-stage stratified random sampling technique.

The schools were stratified into all-boys', all-girls', and coeducational schools. Then one school was randomly selected from each stratum. A total of three public schools were studied. Participants were proportionately selected from each school according to the school's population by multiplying the school's population with the sampling fraction (sample size/total population of selected schools). In each school, the proportional allocation was also applied to obtain the sample size for each grade. An arm was chosen from each grade by simple random sampling method. Where the allocated participants' number slightly differed from the size of the arm, the entire arm was studied. Otherwise, the students were randomly selected using the class register as sampling frame. The male: female ratio of the classes in the co-educational school was approximately $1: 1$ so there was no need to stratify them according to sex except where the number differed significantly from allocated number of participants.

\section{Data Collection}

Parents were notified in advance that interview as well as BP and anthropometric measurements would be carried out on their children by a letter and a consent form. The form was to be filled, signed and returned if the parents consented to the study. In addition, assent of each participant was sought verbally prior to enrolment into the study. Where consent and assent could not be obtained, the student was not enrolled. Students who volunteered history of chronic diseases (including HIV infection, asthma, renal or cardiovascular diseases) were also excluded from the study.

An interviewer administered questionnaire was administered to each eligible student. The questionnaire captured information on date of birth, gender, class in school, family size, parental occupation and education. Physical activity was assessed by asking about the type of sports and games the students were regularly involved in, as well as the frequency and duration of activities on a weekly basis.

The second phase of the study involved physical examination of the students and measurement of height, weight, waist circumference and blood pressure. The students were examined in their school uniforms without cardigans, shoes and socks. Weights of the students were measured using a ZT-120 Health scale, to the nearest $0.5 \mathrm{~kg}$.

The height was measured with a ZT-120 Stadiometer that had a moveable headpiece perpendicular to the vertical backboard. The student stood with the heels, buttocks, shoulders and head touching the vertical backboard, the neck slightly stretched and eyes looking directly ahead. The headpiece was gently brought down until it compressed the hair without exerting any pressure on the head. The measurement was read with the eyes directly facing the level of the headboard in the horizontal plane and was recorded to the nearest $0.5 \mathrm{~cm}$.

Blood pressure was measured using appropriately sized cuff Accoson mercury sphygmomanometer (model DEKAMET MK.3 made in England) and Littman Classic II stethoscope while taking the following precautions: Each student was made to rest for ten minutes seated comfortably before the first reading was taken. The student sat upright with their upper arm positioned to the heart level and feet flat on the floor. Excess clothing that could interfere with BP cuff or constrict blood flow in the arm was removed. The cuff was placed on the subject's arm after palpation of the brachial artery. It was ensured that the artery marker pointed to the brachial artery. The cuff was wrapped snuggly around the student's arm with the width of the cuff covering $75 \%$ of subject's arm. The length covered more than $80 \%$ of the arm's circumference. The cuff was inflated while the radial pulse was felt, and on its disappearance, the cuff was deflated for the auscultation method. On the same arm that the BP cuff was placed, the ante-cubital fossa was palpated to locate the strongest pulse. The bell of the stethoscope was placed over the brachial artery at this position. The cuff was inflated as the heart sounds were listened to until no heart sound was heard, usually about 20 to $40 \mathrm{mmHg}$ above the person's normal systolic reading. The cuff was then slowly deflated by $2-3 \mathrm{mmHg}$ as recommended by American Heart Association. The first occurrence of rhythmic sounds (1st Korotkoff) heard as the blood begins to flow through the artery was the systolic pressure. Deflation continued until the disappearance or fifth Korotkoff sound was heard. This was the diastolic reading [1], [16], [17]. Second and third BP readings were taken at five-minute intervals. A mean of the three measurements was taken as the BP of the child.

The waist circumference was obtained at the end of several consecutive natural breaths, at a level parallel to the floor, midpoint between the lower margin of the last palpable rib and the top of the iliac crest in the mid axillary line [18]. A stretch-resistant tape was snugly wrapped around the abdomen in a non-constricting manner. The tape was kept level and parallel to the floor at the point of measurement with the subject standing upright, arms relaxed at the side and feet evenly spread apart, allowing even distribution of the body weight.

Physical activity, for the purposes of this study, included personal exercises - planned, structured, repetitive, strength 
and resistance training; school sporting activities - track and field games; cycling, skipping, brisk walking, dancing, soccer, basketball, etc. The more vigorous activities performed at least for an hour every day of the week, were categorized as intensive. Moderate activities like brisk walking, stationary exercises, table tennis carried out for about an hour three to five days a week constituted moderate physical activity. Occasional walks with a frequency less than three days a week, and duration not up to an hour was classified as minimal physical activity.

The parents/guardians of participants who were found to have hypertension or pre-hypertension were notified, and the students were referred to Nnamdi Azikiwe University Teaching Hospital for further evaluation and follow-up. At the end of the study, health talks were carried out in studied schools on hypertension and avoidance of associated modifiable risk factors.

\section{Data Analysis}

All data management and statistical analysis were carried out using Statistical Package for Social Sciences (SPSS) (IBM, Chicago IL, USA) software version 20. The mean and standard deviation as well as the median and interquartile range of systolic and diastolic BP for age and sex were calculated using univariate analysis. Using Kolmogorov Smirnov Test, the p-value for the mean systolic and diastolic BP were 0.026 and $<0.001$, respectively, implying that they were not normally distributed. The mean systolic and diastolic BP was compared across different ages using KruskaL-Wallis test for both gender while MannWhitney U test was used to compare the mean systolic and diastolic BP between males and females. Chi-square test was used to compare relationship between categorical variables. Where assumptions for Chi-square test was violated, Fisher's exact test was used. Level of significance was set at $\mathrm{p}<0.05$ and $95 \%$ confidence interval. To adjust for confounders, factors significantly associated with abnormal BP was further analyzed using binary logistic regression analysis.

\section{RESULTS}

A total of 593 students were enrolled in the study -289 boys and 304 girls. The characteristics of the subjects are outlined in Table I.

The mean SBP seemed to increase with age, while the mean DBP did not vary much across the ages but seemed to be higher for girls than boys (Table II). Among the males, the mean systolic BP varied significantly with age $(\mathrm{p}<0.00)$ while the variation in mean diastolic BP was not statistically significant $(\mathrm{p}=0.976)$. On the other hand, the variation of the mean systolic $(p=0.004)$ and diastolic $(p=0.031)$ BP with age was statistically significant among the females. When both genders were combined, the mean systolic BP varied significantly with age $(\mathrm{p}<0.001)$ while the variation in mean diastolic BP was not statistically significant $(\mathrm{p}=0.081)$. The mean systolic and diastolic BP varied significantly between both sexes $(\mathrm{p}<0.001)$.

Among the students $8.4 \%$ had systolic hypertension and $6.6 \%$ systolic prehypertension; $5.7 \%$ had diastolic hypertension and $11.8 \%$ diastolic prehypertension. Fourteen students (2.4\%) had combined systolic and diastolic hypertension, while eight $(1.4 \%)$ had combined systolic and diastolic prehypertension. Prevalence of systolic hypertension in girls was $14.1 \%$ and boys $2.4 \%$, while prehypertension was $11.2 \%$ and $1.7 \%$ respectively.

Prevalence of diastolic hypertension in girls was $7.2 \%$ and boys $4.2 \%$, while prehypertension was $12.5 \%$ and $11.1 \%$ respectively.

Table III shows that there was no significant difference in the prevalence of systolic hypertension or pre-hypertension between early (10-14 years) and late (15-17 years) adolescents in both sexes. However, early adolescent males were more likely to have diastolic hypertension and prehypertension compared to late adolescent males $(\mathrm{p}=0.023)$. There was no difference in the prevalence of hypertension or pre-hypertension between early and late adolescent females.

TABLE I: SOCIO-DEMOGR APHIC AND PHYSICAL CHARACTERISTICS OF

\begin{tabular}{|c|c|}
\hline \multicolumn{2}{|c|}{ SUBJECTS } \\
\hline Characteristic & Proportion (\%) \\
\hline \multicolumn{2}{|l|}{ Age (years) } \\
\hline 10 & $3(0.5)$ \\
\hline 11 & $12(2.0)$ \\
\hline 12 & $59(9.9)$ \\
\hline 13 & $116(19.6)$ \\
\hline 14 & $122(20.6)$ \\
\hline 15 & $124(20.9)$ \\
\hline 16 & $102(17.2)$ \\
\hline 17 & $55(9.3)$ \\
\hline Total & $593(100.0)$ \\
\hline \multicolumn{2}{|l|}{ Gender } \\
\hline Male & $289(48.7)$ \\
\hline Female & $304(51.3)$ \\
\hline Total & $593(100.0)$ \\
\hline \multicolumn{2}{|l|}{ Class in school } \\
\hline Junior secondary & $362(61.0)$ \\
\hline Senior secondary & $231(39.0)$ \\
\hline \multicolumn{2}{|l|}{ Total } \\
\hline \multicolumn{2}{|l|}{ Activity level } \\
\hline Minimal & $422(71.1)$ \\
\hline Moderate & $116(19.6)$ \\
\hline Intensive & $55(9.3)$ \\
\hline \multicolumn{2}{|l|}{ Total } \\
\hline \multicolumn{2}{|l|}{ Socioeconomic level } \\
\hline Upper & $28(4.7)$ \\
\hline Middle & $218(36.8)$ \\
\hline Lower & $347(58.5)$ \\
\hline Total & $593(100.0)$ \\
\hline
\end{tabular}

The prevalence of systolic hypertension and prehypertension varied significantly with sex $(p<0.001)$, activity level $(\mathrm{p}=0.001)$ and assessed anthropometric indices such as BMI $(p=0.003)$, waist circumference $(p=0.032)$ and waist-to-height ratio $(\mathrm{p}=0.006)$ in contrast to socioeconomic level as shown in Table IV.

The prevalence of diastolic hypertension did not vary significantly with sex, socioeconomic level and assessed anthropometric indices as shown in Table V. A higher proportion of subjects who were obese/overweight (using BMI, WC or WHR) or engaged in minimal sporting activities had systolic hypertension compared to others. Systolic hypertension was more evident in the lower socioeconomic levels, those with minimal physical activity, those in the obese/overweight category as evidenced by BMI, WC and WHR. Among obese/overweight students there was a higher prevalence of hypertension - systolic and diastolic. WC was most predictive of high SBP than other indices, while WHR was for high DBP. However, after 
logistic regression analysis, only sex remained significantly associated with having an abnormal systolic BP (hypertension or pre-hypertension) $(\mathrm{p}<0.001, \mathrm{OR}=6.4)$.

\section{DISCUSSION}

It is a well-known fact that hypertension in adults is associated with a high morbidity and mortality. It is also established that high BP in childhood correlates with adult hypertension. A meta-analysis of BP tracking studies confirmed that higher BP in childhood is associated with higher BP in adulthood [19], mandatorily inferring the necessity for early intervention.

In this study the BP was noted to increase with age. This increase occurred in both SBP and DBP. This was the norm in other studies [8], [20], [21]. However, girls had a higher mean SBP than boys. An interesting variant was observed among Tobagonian adolescents [8] where there was an inversion of mean BP with age. Girls 12-13 years had significantly higher mean SBP while those 15-18 years had lower SBP than their male counterparts. Similarly, females 12-14 years had significantly higher mean DBP while those 16-18 years had lower DBP than their male counterparts. This was thought to be due timing of puberty and concomitant changes occurring earlier in females than males.

\begin{tabular}{c|c|c|c|c|c|c|c}
\multicolumn{1}{c}{ TABLE II: MEAN AND MEDIAN BLOO PRESSURE VALUES OF STUDENTS } \\
\hline $\begin{array}{c}\text { Age } \\
\text { (years) }\end{array}$ & $\begin{array}{c}\text { Mean } \\
\text { SBP }\end{array}$ & SD & $\begin{array}{c}\text { Median } \\
\text { SBP }\end{array}$ & $\begin{array}{c}\text { Mean } \\
\text { DBP }\end{array}$ & SD & $\begin{array}{c}\text { Median } \\
\text { DBP }\end{array}$ & N \\
\hline Boys & & & & & & & \\
$\mathbf{1 0}$ & 100.0 & - & - & 70.0 & - & - & 1 \\
$\mathbf{1 1}$ & 95.0 & - & - & 70.0 & - & - & 1 \\
$\mathbf{1 2}$ & 100.7 & 10.54 & 101.0 & 68.3 & 9.99 & 68.0 & 12 \\
$\mathbf{1 3}$ & 103.3 & 11.67 & 101.0 & 68.7 & 8.87 & 70.0 & 67 \\
$\mathbf{1 4}$ & 102.4 & 10.44 & 103.0 & 68.3 & 8.04 & 70.0 & 80 \\
$\mathbf{1 5}$ & 108.2 & 10.42 & 110.0 & 68.5 & 8.67 & 70.0 & 58 \\
$\mathbf{1 6}$ & 110.3 & 11.19 & 110.0 & 69.2 & 8.79 & 70.0 & 50 \\
$\mathbf{1 7}$ & 113.4 & 8.76 & 115.0 & 71.4 & 9.65 & 72.5 & 20 \\
Total & $\mathbf{1 0 5 . 8}$ & $\mathbf{1 1 . 3 2}$ & $\mathbf{1 0 5 . 0}$ & $\mathbf{6 8 . 8}$ & $\mathbf{8 . 6 2}$ & $\mathbf{7 0 . 0}$ & $\mathbf{2 8 9}$ \\
\hline Girls & & & & & & & \\
$\mathbf{1 0}$ & 112.5 & 2.121 & 112.5 & 79.0 & 5.66 & - & 2 \\
$\mathbf{1 1}$ & 112.0 & 11.93 & 111.0 & 69.9 & 13.16 & 70.0 & 11 \\
$\mathbf{1 2}$ & 111.6 & 12.64 & 112.0 & 69.4 & 8.27 & 70.0 & 47 \\
$\mathbf{1 3}$ & 111.0 & 13.96 & 110.0 & 70.5 & 8.49 & 70.0 & 49 \\
$\mathbf{1 4}$ & 116.6 & 8.44 & 115.0 & 72.0 & 6.54 & 70.5 & 42 \\
$\mathbf{1 5}$ & 115.7 & 11.68 & 116.0 & 73.5 & 8.03 & 74.0 & 66 \\
$\mathbf{1 6}$ & 119.4 & 11.93 & 120.5 & 73.7 & 7.57 & 74.5 & 52 \\
$\mathbf{1 7}$ & 117.5 & 11.98 & 117.0 & 73.1 & 6.99 & 73.0 & 35 \\
Total & $\mathbf{1 1 5 . 1}$ & $\mathbf{1 2 . 1 6}$ & $\mathbf{1 1 5 . 0}$ & $\mathbf{7 2 . 1}$ & $\mathbf{8 . 0 8}$ & $\mathbf{7 2 . 0}$ & $\mathbf{3 0 4}$ \\
\hline Both & & & & & & & \\
$\mathbf{1 0}$ & 108.3 & 7.37 & 110.0 & 76.0 & 6.56 & 75.0 & 3 \\
$\mathbf{1 1}$ & 110.6 & 12.38 & 110.5 & 69.9 & 12.55 & 70.0 & 12 \\
$\mathbf{1 2}$ & 109.4 & 12.95 & 110.0 & 69.2 & 8.57 & 70.0 & 59 \\
$\mathbf{1 3}$ & 106.5 & 13.20 & 105.0 & 69.5 & 8.72 & 70.0 & 116 \\
$\mathbf{1 4}$ & 107.3 & 11.89 & 108.0 & 69.6 & 7.73 & 70.0 & 122 \\
$\mathbf{1 5}$ & 112.2 & 11.69 & 114.0 & 71.2 & 8.66 & 71,0 & 124 \\
$\mathbf{1 6}$ & 114.9 & 12.39 & 113.0 & 71.5 & 8.45 & 72.0 & 102 \\
$\mathbf{1 7}$ & 116.0 & 11.02 & 116.0 & 72.5 & 8.01 & 73.0 & 55 \\
Total & $\mathbf{1 1 0 . 6}$ & $\mathbf{1 2 . 6 4}$ & $\mathbf{1 1 0 . 0}$ & $\mathbf{7 0 . 5}$ & $\mathbf{8 . 5 0}$ & $\mathbf{7 0 . 0}$ & $\mathbf{5 9 3}$ \\
\hline & & & & & & & \\
& & & & & \\
\hline
\end{tabular}

The observed prevalence of systolic hypertension was $8.4 \%$, and prehypertension $6.6 \%$, while the respective values for the diastolic were $5.7 \%$ and $11.8 \%$. Combined systolic and diastolic hypertension occurred in $2.4 \%$ of students. These figures parallel findings in other parts of Nigeria [4], [5], [22]. A pooled prevalence for Africa in a systematic review and meta-analysis [23] also fell within the reported range, as are observations from Houston, Texas [24] even though a South African study [25] from KwaZulu-Natal observed a double increase in prevalence. This may be explained by the fact that this population had significant proportions of obesity, hypercholesterolemia, and albuminuria. Adolescents in Kerala, India [9] also exhibited similarly high prevalence needing urgent attention.

Gender differences in hypertension were noted with girls being more hypertensive than boys. This was equally reported in other studies [5], [6]. This may be attributed to the fact that obesity, lack of physical exercise, use of contraceptives, unhealthy diet, stress abound more in females than males.

TABLE III: AGE AND GENDER PREVALENCE OF HYPERTENSION AMONG STUDENTS

\begin{tabular}{|c|c|c|c|c|c|c|}
\hline Gender & $\begin{array}{c}\text { Age } \\
\text { (year) }\end{array}$ & Normal & Prehypertension & Hypertension & Total & P-value \\
\hline \multicolumn{7}{|c|}{ Systolic Blood Pressure N (\%) } \\
\hline \multirow{3}{*}{ Males } & $10-14$ & $\begin{array}{c}156 \\
(96.9) \\
\end{array}$ & $1(0.6)$ & $4(2.5)$ & $\begin{array}{c}161 \\
(100.0) \\
\end{array}$ & \multirow{3}{*}{$0.341^{\mathrm{a}}$} \\
\hline & $15-17$ & $\begin{array}{c}121 \\
(94.5)\end{array}$ & $4(3.1)$ & $3(2.3)$ & $\begin{array}{c}128 \\
(100.0)\end{array}$ & \\
\hline & Total & $\begin{array}{c}277 \\
(95.8) \\
\end{array}$ & $5(1.7)$ & $7(2.4)$ & $\begin{array}{c}289 \\
(100.0) \\
\end{array}$ & \\
\hline \multirow{3}{*}{ Females } & $10-14$ & $\begin{array}{c}116 \\
(76.8)\end{array}$ & $13(8.6)$ & $22(14.6)$ & $\begin{array}{c}151 \\
(100.0)\end{array}$ & \multirow{3}{*}{$0.367^{\mathrm{b}}$} \\
\hline & $15-17$ & $\begin{array}{c}111 \\
(72.5) \\
\end{array}$ & $21(13.7)$ & $21(13.7)$ & $\begin{array}{c}153 \\
(100.0) \\
\end{array}$ & \\
\hline & Total & $\begin{array}{c}227 \\
(74.7) \\
\end{array}$ & $34(11.2)$ & $43(14.1)$ & $\begin{array}{c}304 \\
(100.0) \\
\end{array}$ & \\
\hline \multirow{3}{*}{ Total } & $10-14$ & $\begin{array}{c}272 \\
(87.2) \\
\end{array}$ & $14(4.5)$ & $26(8.3)$ & $\begin{array}{c}312 \\
(100.0) \\
\end{array}$ & \multirow{3}{*}{$0.093^{\mathrm{b}}$} \\
\hline & $15-17$ & $\begin{array}{c}232 \\
(82.6) \\
\end{array}$ & $25(8.9)$ & $24(8.5)$ & $\begin{array}{c}281 \\
(100.0)\end{array}$ & \\
\hline & Total & $\begin{array}{c}504 \\
(85.0) \\
\end{array}$ & $39(6.6)$ & $50(8.4)$ & $\begin{array}{c}593 \\
(100.0) \\
\end{array}$ & \\
\hline \multicolumn{7}{|c|}{ Diastolic Blood Pressure N (\%) } \\
\hline \multirow{3}{*}{ Males } & $10-14$ & $\begin{array}{c}130 \\
(80.7)\end{array}$ & $20(12.4)$ & $11(6.8)$ & $\begin{array}{c}161 \\
(100.0)\end{array}$ & \multirow{3}{*}{$0.023^{\mathrm{b}}$} \\
\hline & $15-17$ & $\begin{array}{c}115 \\
(89.8) \\
\end{array}$ & $12(9.4)$ & $1(0.8)$ & $\begin{array}{c}128 \\
(100.0) \\
\end{array}$ & \\
\hline & Total & $\begin{array}{c}245 \\
(84.8) \\
\end{array}$ & $32(11.1)$ & $12(4.2)$ & $\begin{array}{c}289 \\
(100.0) \\
\end{array}$ & \\
\hline \multirow{3}{*}{ Females } & $10-14$ & $\begin{array}{c}122 \\
(80.8) \\
\end{array}$ & $16(10.6)$ & $13(8.6)$ & $\begin{array}{c}151 \\
(100.0) \\
\end{array}$ & \multirow{3}{*}{$0.436^{\mathrm{b}}$} \\
\hline & $15-17$ & $\begin{array}{c}122 \\
(79.7) \\
\end{array}$ & $22(14.4)$ & $9(5.9)$ & $\begin{array}{c}153 \\
(100.0)\end{array}$ & \\
\hline & Total & $\begin{array}{c}244 \\
(80.3) \\
\end{array}$ & $38(12.5)$ & $22(7.2)$ & $\begin{array}{c}304 \\
(100.0)\end{array}$ & \\
\hline \multirow{3}{*}{ Total } & $10-14$ & $\begin{array}{c}252 \\
(80.8) \\
\end{array}$ & $36(11.5)$ & $24(7.7)$ & $\begin{array}{c}312 \\
(100.0) \\
\end{array}$ & \multirow{3}{*}{$0.097^{\mathrm{b}}$} \\
\hline & $15-17$ & $\begin{array}{c}237 \\
(84.3)\end{array}$ & $34(12.1)$ & $10(3.6)$ & $\begin{array}{c}281 \\
(100.0)\end{array}$ & \\
\hline & Total & $\begin{array}{c}489 \\
(82.5)\end{array}$ & $70(11.8)$ & $34(5.7)$ & $\begin{array}{c}593 \\
(100.0)\end{array}$ & \\
\hline
\end{tabular}

$\mathrm{BP}$ is categorized as normal $\left(<90^{\text {th }}\right.$ percentile for age and gender), hypertension $\left(\geq 95^{\text {th }}\right.$ percentile), and pre-hypertension (between $90^{\text {th }}$ and $95^{\text {th }}$ percentiles)

a. Fisher exact test

b. Pearson Chi-square test

One may also note that hypertension rises with age. Even though hypertension in children is more of the secondary type, essential hypertension becomes significant as age increases. Also, behavioral risk factors tend to affect prevalence in older adolescents.

It has been established that regular exercise can help lower BP in children [26], [27]. 
TABLE IV: SUBJECTS' CHARACTERISTICS AND SYSTOLIC BLOOD PRESSURE

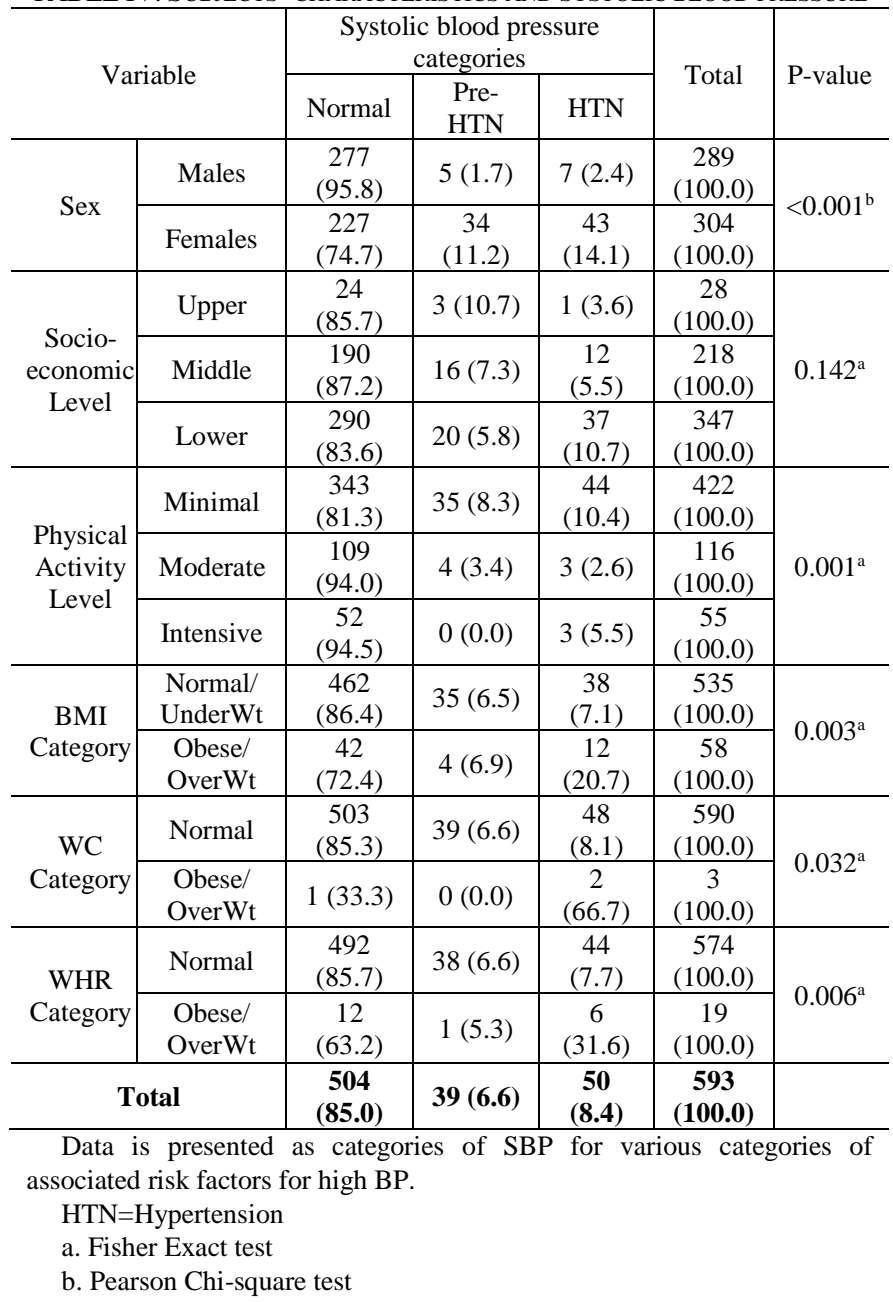

Both systolic and diastolic hypertension was highest amongst the students who had minimal physical activity. More recent studies have also laid credence to the causal relationship between higher physical activity and lower BP in children [28] - [30].

It was observed that as the socioeconomic level reduced the prevalence of hypertension increased. This was also observed by researchers from other climes [13], [14], [31], [32]. Lower socioeconomic status has been associated with a poorer bio-behavioral risk profile and, in turn, with higher SBP [14], [32], [33]. One may not as of necessity ascribe this reason to the finding since the study was not structured in that wise. However, one may opine that these children may not be cushioned from the vagaries of life which in themselves constitute stressors.

Sustained environmental stressors such as noise, overcrowding and violence, or economic stressors such as chronic poverty may influence essential hypertension and related outcomes in children and youth [31]. The higher prevalence of obesity following ingestion of cheaper poorlynourishing foods has also been implicated [13] in causation of high BP in adolescents of low socioeconomic status. The same could not be said of this category of students who were not overly obese.
TABLE V: SUBJECTS' CHARACTERISTICS AND DIASTOLIC BLOOD PRESSURE

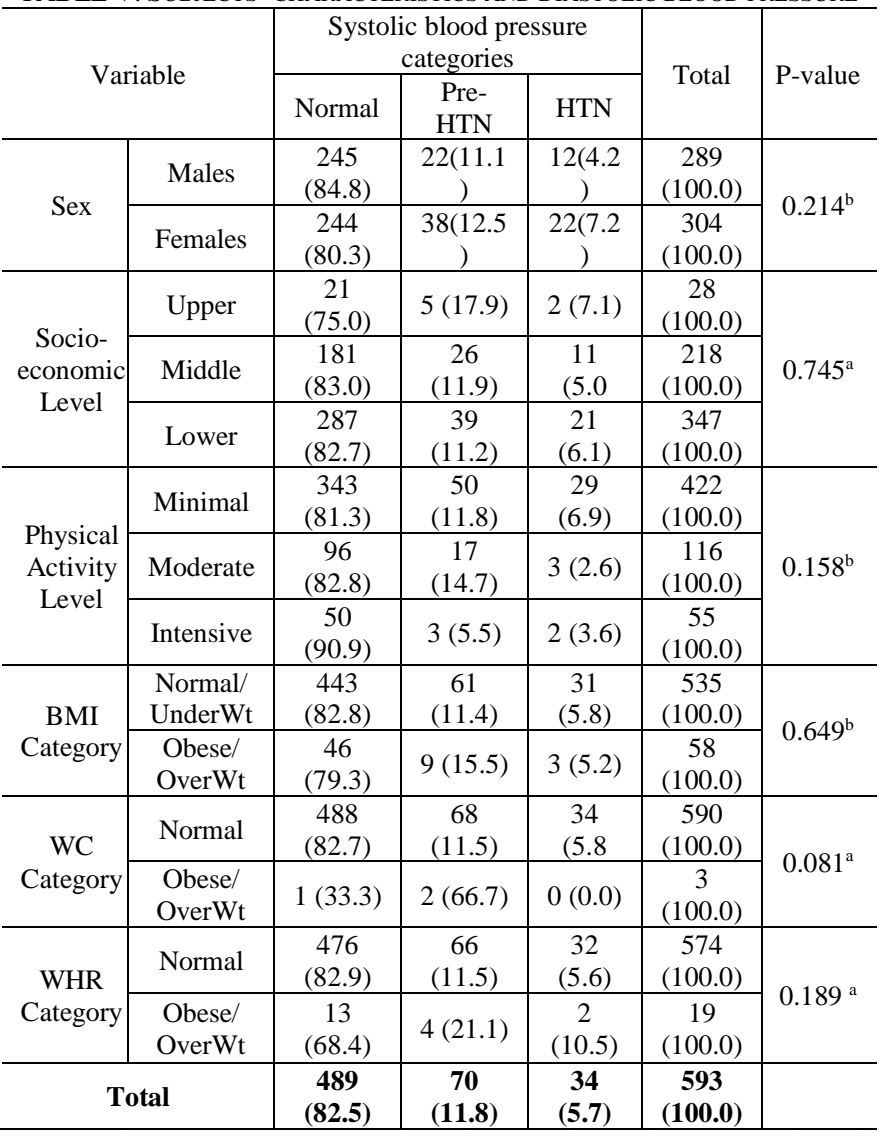

Data is presented as categories of DBP for various categories of associated risk factors for high BP.

HTN=Hypertension;

$\mathrm{NBP}=$ Normal BP;

PHTN=Pre-hypertension

a. Fisher Exact test

b. Pearson Chi-square test

Overweight and obesity are strongly correlated with primary hypertension in children [12]. With increasing BMI, WC and WHR both SBP and DBP significantly increased. This fact was corroborated by other studies [3], [10], [11], [34]. However, WHR and WC seem to be more sensitive predictors of hypertension than BMI - WC of SBP and WHR of DBP respectively. WC measures central obesity, which occurs more in adults than in children. Noronha et al [35] also noted increased SBP associated with increased WC among children and adolescents in Brazil. WHR is a simple, easy and accurate index suitable as a screening tool for obesity in children and adolescents. As an obesity indicator it has come in handy as a useful initial screening tool for high BP in India [36], Taiwan [37] and South Africa [38] although in this study its sensitivity is at par with BMI for SBP and more for DBP.

\section{CONCLUSIONS}

The mean systolic BP significantly varied with age in both sexes. On the other hand, the mean diastolic BP significantly varied with age among the girls but the variation with age was not statistically significant among the boys. Girls significantly have higher mean systolic and diastolic BP compared to boys.

There is a significant prevalence of hypertension among public school students in Nnewi. Girls had higher prevalence of hypertension compared to boys. Obesity 
indices mirror hypertension in children. WC in the obese/overweight category very likely predicts hypertension. Children in the lower socioeconomic level as well as those with minimal physical activity are more prone to hypertension. After logistic regression analysis, only sex remained significantly associated with having abnormal systolic BP (hypertension or prehypertension). The odds of having abnormal BP was six times higher in girls compared to boys.

Our findings highlight the need to strengthen the school health program and ensure periodic monitoring of the BP of adolescents, especially girls. Awareness of identified modifiable risk factors and their prevention should be intensified in schools and among the general population.

\section{CONFLICTS OF INTEREST}

The authors declare that they have no conflict of interest.

\section{ETHICAL APPROVAL AND CONSENT}

Ethical approval was obtained from the institutional ethical committee of Nnamdi Azikiwe University Teaching Hospital. Permission to carry out the study was sought for and obtained from the Zonal Directorate of Post Primary School Service Commission and Anambra State Universal Basic Education Board, Nnewi Zone. Consent of participating school principals, parents/guardians, tutorial staff and students were duly obtained.

\section{DISCLOSURE}

This research did not receive any specific grant from funding agencies in the public, commercial, or not-for-profit sectors.

\section{ACKNOWLEDGMENT}

We would like to thank all the school principals, tutorial staff and the students of the schools that participated in the study. We also express our sincere gratitude to the authorities of the Zonal Directorate of Post Primary School Service Commission and Anambra State Universal Basic Education Board, Nnewi Zone for permitting data collection.

\section{REFERENCES}

[1] National High Blood Pressure Education Program Working Group on Hypertension Control in Children and Adolescents. Update on the 1987 Task Force Report on High Blood Pressure in Children and Adolescents: A Working Group Report from the National High Blood Pressure Education Program. Pediatrics 1996; 98 (4): 649-658. Available at http://pediatrics.aappublications.org/content/98/4/649.

[2] Souza CB, Dourado CS, Mill JG, Salaroli LB, Molina MCB Prevalence of hypertension in children from public schools. Int J Cardiovasc Sci. 2017; 30(1): 42-51.

[3] Mladenova S, Andreenko E. The prevalence of high-normal blood pressure and hypertension among 8 to 15-year-old Bulgarian children and adolescents with various nutritional status (Smolyan Region, 2012-2014). Anthropologist 2015; 21(1,2): 51-60.

[4] Bugaje MA, Yakubu AM, Ogala WN. Prevalence of adolescent hypertension in Zaria. Nigerian Journal of Paediatrics 2005; 32 (4): $77-82$.

[5] Ezeudu EC, Chukwuka JO, Ebenebe JC, Igwe WC, Egbuonu I. Hypertension and prehypertension among adolescents attending secondary schools in urban area of south-east Nigeria. PanAfrican Medical Journal 2018; 31: 145.
[6] Ba HO, Menta I, Camara Y, Sidibe N, Dao A, Sangare I et al Prevalence of high blood pressure (HBP) in the population of 5-17 years in Bamako. Heart and Cardiology: Open Access 2016; 2 (1) http://crescopublications.org/pdf/hcoa/HCOA-2-006.pdf. Article Number: HCOA-2-006.

[7] Mbolla BFE, Okoko AR, Babela JRM, Bowassa GE, Gombet TR, Kimbally-Kaky S. Prehypertension and hypertension among school children in Brazzaville, Congo. International Journal of Hypertension 2014, Article ID 803690, 6 pages. http://dx.doi.org/10.1155/2014/803690.

[8] Nichols S, Cadogan F. Blood pressure and its correlates in Tobagonian adolescents. West Indian Medical Journal 2006; 55 (5): $1-8$.

[9] Tony L, Areekal B, Nair ATS, Ramachandran R, Philip RR, Rajasi RS, et al. Prevalence of hypertension and pre-hypertension among adolescent school children in Thiruvananthapuram, Kerala, India. Int J Community Med Public Health 2016; 3 (12): 3556-3563.

[10] Falkner B, Gidding SS, Ramirez-Garnica G, Wiltrout SA, West D, Rappaport EB. The relationship of body mass index and blood pressure in primary care pediatric patients. J Pediatr 2006; 148(2): 195-200.

[11] Sorof JM, Lai D, Turner J, Poffenbarger T, Portman RJ. Overweight, Ethnicity, and the Prevalence of Hypertension in School-Aged Children. Pediatrics 2004; 113 (3): 475-482.

[12] Riley M, Bluhm B. High blood pressure in children and adolescents. American Family Physician 2012; 85 (7): 693-700.

[13] Soylu A, Kavukcu S, Turkmen M, Cabuk N, Duman M. Effect of socioeconomic status on blood pressure in children living in a developed country. Pediatr Int 2000; 42(1): 37-42.

[14] Brummett BH, Babyak MA, Siegler IC, Shanahan M, Harris KM, Elder GH, et al. Systolic blood pressure, socioeconomic status, and behavioral risk factors in a nationally representative US young adult sample. Hypertension 2011; 58: 161-166.

[15] Oyedeji GA. Socio-economic and cultural background of hospitalized children in Ilesha. Nigerian Journal of Paediatrics 1985; 12: 111-117.

[16] U.S. Department of Health and Human Services. National Institutes of Health. National Heart, Lung, and Blood Institute. The Fourth Report on the Diagnosis, Evaluation, and Treatment of High Blood Pressure in Children and Adolescents. NIH Publication No. 05-5267. Originally printed September 1996 (96-3790). Revised May 2005.

[17] Revelas A, Tahmazidis O. Defining hypertension in children. South African Family Practice 2012; 54(2): 100-105.

[18] World Health Organization. Waist Circumference and Waist-Hip Ratio. Report of a WHO Expert Consultation. Geneva, 8-11 December 2008. World Health Organization 2011.

[19] Chen X, Wang Y. Tracking of blood pressure from childhood to adulthood. A systematic review and meta-regression analysis. Circulation 2008; 117(25): 3171-3180. Available at http://circ.ahajournals.org.18559702.

[20] Moselakgomo VK, Toriola AL, Shaw BS, Goon DT, Akinyemi O. Body mass index, overweight, and blood pressure among adolescent school children in Limpopo provice, South Africa. Rev Paul Pediat 2012; 30 (4): $562-569$.

[21] Sayeemuddin M, Sharma D, Pandita A, Sultana T, Shastri S. Blood pressure profile in school children (6-16 years) of Southern India: a prospective observational study. Frontiers in Pediatrics 2015; 3(24): $1-6$.

[22] Okpokowuruk FS, Akpan MU, Ikpeme EE. Prevalence of hypertension and prehypertension among children and adolescents in a semi-urban area of Uyo Metropolis, Nigeria. Pan African Medical Journal 2017; 28: 303-312.

[23] Noubiap JJ, Essouma M, Bigna JJ, Jingi AM, Aminde LN, Nansseu JR. Prevalence of elevated blood pressure in children and adolescents in Africa: a systematic review and meta-analysis. Lancet Public Health 2017; 2: e375-386.

[24] Bell CS, Samuel JP, Samuels JA. Prevalence of hypertension in children: Applying the new American Academy of Pediatrics Clinical Practice Guideline. Hypertension 2019; 73: 148-152.

[25] Bhimma R, Naicker E, Gounden V, Nandlal L, Connolly C, Hariparshad S. Prevalence of primary hypertension and risk factors in Grade XII learners in KwaZulu-Natal, South Africa. International Journal of Hypertension. Hindawi. Volume 2018. Article ID 3848591 , 9 pages. https://doi.org/10.1155/2018/3848591.

[26] Physical exercise in the management of hypertension: a consensus statement by the World Hypertension League. J Hypertens 1991; 9 (3): 283-287.

[27] Morales MC, Coplan NL, Zabetakis P, Gleim GW. Hypertension: the acute and chronic response to exercise. Am Heart J 1991; 122 (1Pt1): 264-266. Available at https://doi.org/10.1016/0002-8703(91)90797L. 
[28] Leary SD, Ness AR, Smith GD, Mattocks C, Deere K, Blair SN, et al. physical activity and blood pressure in childhood: Findings from a population-based study. Hypertension 2008; 51: 92-98.

[29] Knowles G, Pallan M, Thomas GN, Ekelund U, Cheng KK, Barrett T, et al. Physical activity and blood pressure in primary school children: A longitudinal study. Hypertension 2013; 61: 70-75.

[30] Durrani AM, Fatima W. Effect of physical activity on blood pressure distribution among children. Advances in Public Health. Hindawi Publishing Corporation. Volume 2015, Article ID 379314, 4 pages. http://dx.doi.org/10.1155/2015/379314.

[31] Wilson DK, Kliewer W, Plybon L. Sica DA. Socioeconomic status and blood pressure reactivity in healthy black adolescents. Hypertension 2000; 35 (part 2): 496-500.

[32] Kaczmarek M, Stawinska-Witoszynska B, Krzyzaniak A, Krzywinska-Wiewiorowska M, Siwinska A. Who is at higher risk of hypertension? Socioeconomic status differences in blood pressure among Polish adolescents: a population-based ADOPOLNOR study. Eur J Paediatr 2015; 174: 1461-1473.

[33] Chaix, B, Bean K, Leal C, Thomas F, Harvard S, Evans D, et al. Individual/neighborhood social factors and blood pressure in the RECORD Cohort Study: which risk factors explain the associations? Hypertension 2010; 55: 769-775.

[34] Isezuo KO, Jiya NM, Audu LI, Ibitoye PK, Sani UM, Yusuf T, et al. Blood pressure pattern and relationship with body mass index among apparently healthy secondary school students in Sokoto metropolis, Nigeria. South African Journal of Child Health 2018; 12 (3): 105110.

[35] Noronha JAF, Ramos ALC, Ramos AT, Cardoso MAA, de Carvalho DF, Medeiros CCM. High blood pressure in overweight children and adolescents. Journal of Human Growth and Development 2012; 22(2): 196-201.

[36] Mishra PE, Shastri L, Thomas T, Duggan C, Bosch R, McDonald $\mathrm{CM}$, et al. Waist-to-height ratio as an indicator of high blood pressure in urban Indian school children. Indian Pediatrics 2015; 52: 773-778.

[37] Chen TL, Choy CS, Chan WY, Chen CH, Liao CC. Waist-to-height ratio and elevated blood pressure among

[38] children in Taiwan. Indian Pediatrics 2012; 49: 463-466.

[39] Motswagole BS, Kruger HS, Faber M, van Rooyen JM, de Ridder JH. The sensitivity of waist-to-height ratio in identifying children with high blood pressure. Cardiovascular Journal of Africa 2011; 22 (4): 208-211.

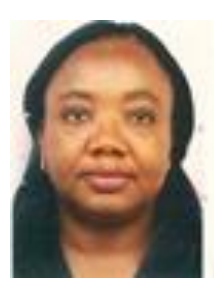

Dr. Ebelechuku Francesca Ugochukwu Professor of Paediatrics and Chief Consultant Paediatrician, MB.BS, FWACP (Paediatrics).

Past Head of Paediatrics and Past Dean, Faculty of Medicine.

Dept of Paediatrics, Nnamdi Azikiwe University, Awka, Nigeria.

Special interest in Paediatric Infectious Diseases (HIV \& TB), Adolescent Medicine, Paediatric Nutrition \& Neonatology.

Dr.Chinyere Ukamaka Onubogu. MB. BS,

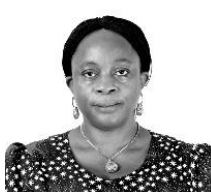
FWACP (Paediatrics). Consultant Paediatrician and Lecturer at Dept of Paediatrics, Nnamdi Azikiwe University, Awka.

Author of many peer reviewed publications. Special interest in Paediatric Infectious Diseases (TB \& HIV), Paediatric Nutrition and Adolescent Health.

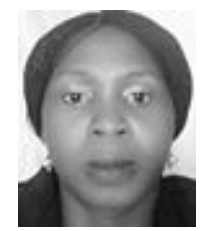

Dr. Victoria C. Ofora. MB. BS, FWACP (Paediatrics). Dept of Paediatrics, Nnamdi Azikiwe University Teaching Hospital, Nnewi.

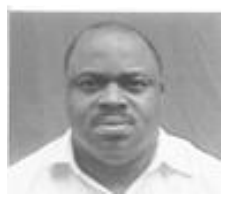

Dr. Kenneth N. Okeke MB. BS, FMCPaed, Consultant Paediatrician and Lecturer Nnamdi Azikiwe University, Awka.

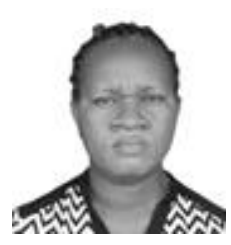

Dr. Chinenye MaryQueen Uju - MB. BS. Senior Registrar in Paediatrics at Nnamdi Azikiwe University Teaching Hospital, Nnewi. 